\title{
Pedagogies of the futures: Shifting the educational paradigms
}

\author{
Jelena Cingel Bodinet ${ }^{1}$
}

Received: 31 August 2016 / Accepted: 24 November 2016/Published online: 7 December 2016

(C) The Author(s) 2016. This article is published with open access at Springerlink.com

\begin{abstract}
Focusing on an educational paradigm rooted in critical pedagogy, the socratic method, futures studies, and peace education, this essay takes the position that classrooms of the future should be transformed into safe harbors where students are afforded the opportunity to explore, deconstruct and share knowledge of themselves, their experiences, and the world in which they live. Drawing upon experience as a professor of futures studies, peace studies, and international relations, the author argues that, regardless of the subject being taught, students should be active participants in a classroom environment where the professor guides understanding primarily as an individual contributor. The essay embodies Einstein's assertion that "we can not solve our problems with the same level of thinking that created them", by arguing that in such 'incubatorial' classrooms, students and teachers strive, together, to evolve their mutual understanding of the world, which, as knowledge, forms a basis for their collective reality.
\end{abstract}

Keywords Futures studies $\cdot$ Peace studies $\cdot$ Critical pedagogy $\cdot$ Active learning $\cdot$ Student-centered learning . Socratic method $\cdot$ Engaged pedagogy

Jelena Cingel Bodinet

jbodinet@sdccd.edu

1 Behavioral Sciences Department, San Diego City College, 1313 Park Blvd, San Diego, CA 92101, USA

\section{Education as the key}

Education is the most powerful weapon which you can use to change the world.

-Nelson Mandela

The present-day educational system was created during the industrial age [1: 13] (1760-1860) and is largely geared toward the knowledge, values, and norms of the 18th and 19th centuries. Both society and the world in which we live have changed drastically since the industrial era and continue to change exponentially. Yet, changes within our educational system are proceeding at a much slower rate. Sir Ken Robins, an internationally celebrated leader in education and author of several books, argues that the current educational system runs on outdated needs and assumptions, producing an output of students ready to tackle the challenges of a former world [1]. To achieve this end, the present system first divides students into batches, and separates knowledge into segments [2]. It then becomes the instructor's primary role to 'transfer' knowledge to the student, with the expectation that the student will memorize the information and reassemble it on cue. While at times valuable, this "banking" concept of education tends to create an atmosphere in which, according to Paulo Freire, "the people themselves (...) are filed away through the lack of creativity, transformation, and knowledge in this (at best) misguided system" [3: 72].

Building on poststructuralism and social constructivism, as well as on Freire's argument that "knowledge emerges only through invention and re-invention, through the restless, 
impatient continuing, hopeful inquiry human beings pursue in the world, with the world, and with each other" [3: 72], this article argues for the creation of a future educational experience that will facilitate more than just the transfer of information. The classroom of the future, 2030 and beyond, should allow for the creation of a space in which students and educators can allow themselves to be present as human beings and, through this, come together in a holistic learning experience. Such classrooms offer students the opportunity to deconstruct and share knowledge of themselves, their experiences and the worlds in which they live. Focus is placed upon critical thinking and deep listening, with the intent of learning from the experiences of others. It should be a primary goal that graduates of such 'incubatorial' classrooms enter the "real" world with a better understanding of themselves, their abilities and desires, as well as a more profound understanding of their fellow humans and the world they inhabit. Through this, these graduates will be better equipped to handle the mounting challenges humanity presently faces. Global climate change, resource depletion, pollution, toxic waste, weapons of mass destruction, societal inequalities, and loss of biodiversity are among the issues the next few generations must tackle with urgency ${ }^{1}$ [4]. In line with Einstein's assertion that "we cannot solve our problems with the same level of thinking that created them", if society is to start thinking differently, our educational systems must be structured so as to nurture different traits in society. If our aim is to engender positive change for the future, which is able to assist in the overcoming of the aforementioned challenges, a centuries-old educational system is most certainly barren soil.

\section{The way forward}

"The secret of change is to focus all your energy not into fighting the old but building of the new."

- Socrates

Education is a powerful tool that should be used to transform society into being more future-oriented, sustainable and peaceful. In an effort to create such a society, we must reexamine the foundations of education by posing several questions, including:

- What is being taught (what subjects and how are they organized and presented)?

\footnotetext{
${ }^{1}$ This point is similarly argued in Cynthia Luna Scott's 2015 article, The Futures of Learning 3, "Saavedra and Opfer (2012) argue that learners must hone their skills and enhance their learning as a matter of urgency to be able to address persistent global challenges" [4].
}

- Who is being taught (who are the students and what are the educators' perceptions of the student population)?

- Who is doing the teaching (what is the educator's background - e.g., gender, race, socio-economic status - especially as compared to or contrasted with the student population)? and

- From whose perspective (educator and students should be aware of the subjectivity in any text or information provided)?

These questions help to gain clarity and assist in the necessary deconstruction of the pedagogical processes that are being utilized, in addition to allowing for a clearer articulation of our desired pedagogical processes for 2030 and beyond. How we answer the questions above will influence our teaching theories, methods, and tools.

Today, knowledge is generally segmented into four main disciplines: Humanities (e.g., Languages/Literature, History, Philosophy), Social Sciences (e.g., Anthropology, Sociology, Political Science), Natural Sciences (e.g., Biology, Chemistry, Physics) and Formal Sciences (e.g., Mathematics, Logic). This system allows for the organization of knowledge and, through this organization, provides a sense of control over the overwhelming amount of information that humans currently possess. In such a system, individuals are able to specialize in a certain discipline and become experts in it, presiding over a large amount of knowledge in one particular field. This can be very beneficial in many cases, but at times such "categorizations" may prevent us from being able to have a more holistic point of view.

Various new fields of inquiry are questioning this organized structure through the use of multidisciplinary ${ }^{2}$ and interdisciplinary ${ }^{3}$ approaches. Contemporary disciplines such as Futures Studies, Peace Studies, and Gender Studies draw upon concepts stemming from various existing and established disciplines (e.g. anthropology, history, psychology, political science, sociology, economics, philosophy) to gain a fresh perspective on existing problems, as well as to address the problems using truly innovative solutions. Such programs are becoming popular with students and, thus, their availability is increasing at institutions of higher education around the world. However, one impediment to a more rapid adoption of such interdisciplinary subjects is that these subjects often

\footnotetext{
${ }^{2}$ Multidisciplinarity is the study of several disciplines simultaneously. "Multidisciplinarity brings a plus to the discipline in question (the history of art or philosophy in our examples), but this 'plus' is always in the exclusive service of the home discipline. In other words, the multidisciplinary approach overflows disciplinary boundaries while its goal remains limited to the framework of disciplinary research.” As quoted in [5].

${ }^{3}$ An interdisciplinary program synthesizes perspectives, knowledge, and skills from various established disciplines to examine a central theme or issue. For instance, peace studies draws heavily from various disciplines (political science, history, sociology, etc.), yet remains separate from them and seeks to better understand how we can create a more peaceful world.
} 
face various roadblocks in the bureaucracies of academia where deans and chairs are unsure of how to categorize the new subject and hire appropriate professors. This lack of institutional support could threaten the existence of these innovative courses, despite their popularity with the student population. If we are to allow for a paradigm shift in the organization of knowledge, a new understanding at the leadership level is necessary; this is not surprising, as present leadership is a product of the self-same system, thus perpetuated.

The UNESCO report on Futures of Learning argues that this effort to change must be multi-national, "will require professional, organizational and political action" and "must take place not just inside classrooms, schools and central management, but also outside - in the culture, systems, policies and structures that shape and support what happens in the classroom" [4: 16]. One way to support such a paradigm shift, then, is to lobby in favor of interdisciplinary programs at various educational institutions as well as to continue to teach such courses using innovative approaches. All the while, we must continue to be aware of the kind of population we are serving as educators, as it becomes a crucial aspect of our ability to offer appropriate courses that are taught in a way that resonates with that particular student population. As experienced educators, we need to be willing to get to know our students and understand who they are, beyond the usual statistics such as gender, race, age, socio-economic status, etc.

"Freire argued that teachers uncover materials and generative themes based on their emerging knowledge of students and their sociocultural backgrounds. eachers come to understand the ways students perceive themselves and their interrelationships with other people and their social reality. This information is essential to the critical pedagogical act as it helps teachers understand the ways they make sense of schooling and their lived words. With these understandings in mind, critical teachers come to know what and how students make meaning. This enables teachers to construct pedagogies that engage the impassioned spirit of students in ways that moves them to learn what they don't know and to identify what they want to know"

\section{[6: 19-20].}

Thus, we need to allow our students to, first, educate us, the educators, on their backgrounds, lives and beliefs so that we are better able to understand how we can help these individuals learn what we, as a society, wish them to know. Through this, we are able to assist them in reaching their highest potential. Using this process we might also gain insight into the various teaching methods that have an increased effect on each particular student population.

\section{"Oh Captain, my Captain"}

"Just when you think you know something, you have to look at in another way. Even though it may seem silly or wrong, you must try."

—Robin Williams (as John Keating in Dead Poets Society)

When I first started teaching at San Diego City College in 2008, an institution where I have taught Futures Studies, Peace Studies, International Relations, Comparative Politics and Gender Studies, I lectured the entirety of most class meetings. I was experienced as a teacher, but this was my first time teaching at the college level. As such, I started by imitating the kind of teaching style that I had experienced most of my life; the teacher-centered approach. At this time in my career this made sense; I could use the text-books that were recommended by my colleagues and create PowerPoint presentations that could easily be re-used each semester. I was meeting the standards of teaching with which I was familiar. This approach worked for a while, but I felt very distant from my students and thought that I was not being as effective as I could be. I believed that a discussion covering the PowerPoint presentations would benefit the class, yet the students were not very interested in joining the discussion, nor were they interested in asking their own questions. While some of the students were content with, effectively, the status quo, there were a few individuals who were bold enough to question my methods, my teaching style and the content I was covering. In my Comparative Politics courses, students wondered how and why we spent so much time studying the state structure of the United Kingdom and were not covering contemporary issues, such as immigration and terrorism, in more detail. In my International Relations courses, they questioned why we spent so much time on Liberalism and Realism, and not as much on other approaches such as Constructivism, Poststructuralism, Marxism, Postcolonialism, Feminism, etc.

Where other professors might become defensive and double down on their style, I chose to listen deeply and learn from what I saw to be a very diverse and intelligent student body. I heard and understood that this population was feeling left out from the wider discourse of higher education, as they could not picture themselves in any part of it. Realism and Liberalism are rooted in Western thought and remain dominated by mostly male individuals of European heritage and higher social ranking. These theories were addressing problems that seemed irrelevant to my students, through a language that was foreign to them. Yet, areas of study such as Postcolonialism and Feminism are spaces that allow such students to identify with both the message and the messenger. Many of the texts in the forementioned subjects were written 
by the oppressed or subaltern, and are addressed, in part, to that very same group. In many cases, students in my classes (and I think young people in general can fall into this group) feel oppressed or 'othered' in their personal lives, and, so, reading postcolonial or feminist texts addresses a part of them that might not have been addressed through previous (formal) educational experience. As a consequence of me listening and shifting my focus, the students suddenly engaged in the subject matter much more richly; they were interested in the readings, which now gave them a sense of validation (of both language and content), and through this they began to contribute more significantly in class. Here is where true learning begins to take place - where students are able to see themselves as part of their newly acquired knowledge and can begin to recognize that they, in fact, also play a part in this bigger puzzle that they are just starting to understand [4: 6]. Such learning allows students to gain a better understanding of themselves and the world in which they live, creating a space for much more aware and active social participants.

Beyond a pivot in the subject matter of readings, I also began to realize that a "'transmission' model is highly ineffective for teaching twenty-first century skills" [4: 2]. The various theories and methodological approaches I was teaching questioned many of the structures and "social inventions"4 that make up and control our world, including teachercentered pedagogical approaches. Specifically, it was poststructuralism, a theory highly concerned with power structures and the idea of hegemony, that equipped me with a theoretical basis for re-examining the lecture-based pedagogical model as the appropriate tool for teaching. As we read and discussed ideas concerning cycles of oppression, social inequalities, reproduction of social structures, and others, I became conscious of the fact that the lecture-based pedagogical approach I was utilizing was, in fact, both a by-product of oppressive social structures as well as a system that was allowing such structures to perpetuate. As Michel Foucault, the prominent French philosopher, noted:

"Education may well be, as of right, the instrument whereby every individual, in a society like our own, can gain access to any kind of discourse. But we well know that in its distribution, in what it permits and in what it prevents, it follows the well-trodden battle-lines of social conflict. Every education system is a political means of maintaining or of modifying the appropriation of discourse, with the knowledge and the powers it carries with it." [8: 227]

Bearing this in mind, it follows that education has a prominent role to play in the construction of systems of power; privilege and oppression; and the general discourse of our

\footnotetext{
${ }^{4}$ In the essay "Society as a social invention and you as a social inventor" (1993) by Dr. Jim Dator, Professor and Director of the Hawaii Research Center for Futures Studies at the University of Hawaii, Manoa, posits that everything around us is a social invention. The term "social invention" is borrowed from this essay [7].
}

social realities. Teaching approaches are the starting point of such social construction, similar to how a font affects more meaning or emotion in the written word, and so the approach should reflect the kind of world that we hope to create.

Social constructivism is another theoretical approach which impacted my classroom structure. This theory emphasizes the idea "that human development is socially situated and knowledge is constructed through interaction with others" [9: 1] and holds that "humans create meaning as opposed to acquiring it" [10: 55]. Thus, our ability to learn becomes closely connected to our involvement in the learning process. "For this reason, it is critical that learning occurs in realistic settings and that the selected learning tasks be relevant to the students' lived experiences" [10:56]. Following this constructivist point of view, we move away from the model of thinking that knowledge is objective, and begin to understand that knowledge is linked to the historical context of the material being studied, as well as the students' lived experiences. Once these are taken into consideration, a new learning structure emerges, one that encourages the learner to "construct their own understandings and then to validate, through social negotiation, these new perspectives" [10:57-58]. Understanding that development and acquisition of knowledge is directly related to social interaction, lived experience and historical context caused me to create student-centered classrooms which would allow and assist students to learn on their own and in groups.

Various researchers have published studies to support such student-centered approaches, as was beautifully summarized in Cynthia Luna Scott's "Futures of Learning 3: What kind of Pedagogies for the 21st Century?" Multiple research studies are quoted therein, which substantiate the idea that "pedagogies that support deeper learning include personalized learning strategies, collaborative learning and informal learning" [4: 2]. Furthermore, Scott asserts that:

"[t]here is compelling evidence that enquiry based collaborative approaches to learning benefit both individual and collective knowledge growth. Learners engaged in enquiry-based learning develop content knowledge and learn increasingly important twenty-first century skills, such as the ability to work in teams, solve complex problems, and apply knowledge gained through one lesson or task to other circumstances (Barron and DarlingHammond, 2008, p. 12) (...) Leadbeater (2008) stresses that 'learning is best done with people rather than to or for them. It is more effective when learners are participants rather than merely recipients'. Deeper learning is supported by 'doing and using' and students are motivated through highly participative and dynamic learning activities. Emphasis is placed on the process of teaching and learning, with effective learning organized to create maximum opportunities for learners and teachers to talk, 
meet, ask questions, share information and exchange ideas. Learners are more engaged in learning and can tackle bigger, more sophisticated projects when they collaborate with others both inside school (Vockley and P21, 2007) and within and between communities (Carneiro, 2007). Ultimately, there are few places and situations in the current workplace where people truly work alone. The ability to collaborate and communicate is therefore essential." [4: 6-7]

Of a similar mindset, I chose to incorporate studentcentered teaching methods, such as structured discussions, small group work (e.g. groups projects or group presentations), and workshops, while cutting back on lectures and teacher-centered teaching methods. Through this new structure, students were able to learn from each other and work together in new ways. As a result of my shift toward more student-centered teaching methods I could perceive (in some classes more so than others, due to the differences in personalities that make up each group) a sense of community arising in my classrooms. Students started to engage each other in a different way, becoming friends, and creating a sense of togetherness in the classroom, which, in turn, created a very positive and supportive learning environment, because

“(...)individuals learn best when they are supported by the right set of relationships that motivate, engage, care about and reward them... Such relationships offer them opportunities to actively participate in learning and cocreate new knowledge." [4: 10]

Over time, I have incorporated several methods into my teaching repertoire, most of which have proven to be very appropriate and successful with the student population at San Diego City College. It is such student-centered teaching methods, which, I argue, should become a necessary part of classrooms of 2030 and beyond. The remainder of this article is dedicated to the following active learning methods I employ today, and strongly urge other educators to adopt in the future: meditation, visioning workshops, various types of discussions and small group work, and (shortened) active teacher and guest lectures.

\section{Meditation as a teaching tool}

"If every eight year old in the world is taught meditation, we will eliminate violence from the world within one generation."

-The Dalai Lama
Both long-term practice in various cultures and modern scientific research have shown that meditation is an excellent tool that helps individuals reduce stress, clear the mind and allow for better concentration, among other benefits. For centuries, various groups (Buddhists, Hindus, etc.) have used meditation due to its lasting impacts on the body and mind, including a calming and transformational effect that improves health and emotional positivity [11]. Furthermore, studies have more recently found that meditation can be used as a positive tool in educational settings. In their paper "Integrating Mindfulness Training into K-12 Education: Fostering the Resilience of Teachers and Students", John Meiklejohn et al. argue that:

"Research on the neurobiology of mindfulness in adults suggests that sustained mindfulness practice can enhance attentional and emotional self-regulation and promote flexibility, pointing toward significant potential benefits for both teachers and students (...) Since 2005, 14 studies of programs that directly train students in mindfulness have collectively demonstrated a range of cognitive, social, and psychological benefits to both elementary (six studies) and high school (eight studies) students. These include improvements in working memory, attention, academic skills, social skills, emotional regulation, and self-esteem, as well as self-reported improvements in mood and decreases in anxiety, stress, and fatigue.” [12]

Various additional studies in schools across the United States have shown that meditation has been instrumental in both academic performance, by helping students to improve scores on validated attention-skills tests [13] and in resulting in 38\% fewer suspension days, $25 \%$ fewer class absences, $50 \%$ fewer rule infractions, and $8 \%$ reduction of aggressive behavior [14].

Based upon the aforementioned ancient traditions, whose effects are substantiated by recent scientific studies, I decided to introduce a five-minute mindfulness meditation to the beginning of most courses that I teach at San Diego City College. This is a practice that is democratically voted upon at the beginning of each semester, thus it is something that the students, themselves, ultimately have to choose to incorporate into their day. When included, this time allows the group to come together and "arrive" in the classroom space and become more present and aware of their surroundings. The students find this time to be extremely valuable, as it's "the only time in the day I get to just have some peace and just be". 5

In an effort to support various types of individuals, students are offered two different options at the beginning of each session. For the meditation beginner, it is important to have options to work with, as they should not be discouraged from

\footnotetext{
${ }_{5}^{5}$ Anonymous student in Peace Studies 101 class, San Diego City College, Spring 2016.
} 
continuing the practice when they do not feel comfortable with one way or another. One option that can be given is to simply focus on the breath; as thoughts come up, label them as thoughts and allow them to dissipate, but not to engage with the thoughts at the moment. With the other option, students are encouraged to pay very close attention to what is occurring inside of themselves and to become aware of their bodies, their thoughts and their feelings, noting things that they might have missed or things that need attention. Students are reminded to withhold judgement during meditation, regardless of the thoughts and feelings that might arise. At times, we may try a different meditation approach, such as a recorded guided meditation by another person or by focusing on a specific issue that we are working on at the time.

Thus, mindfulness practices not only offer the student assistance when learning academic material, but also create space for the student to become more familiar with the self, beyond textbook knowledge.

\section{The visioning workshop ${ }^{6}$}

"A vision is not just a picture of what could be; it is an appeal to our better selves, a call to become something more."

\section{— Rosabeth Moss Kanter}

Originally developed by the European futurist and cofounder of the World Futures Studies Federation, Robert Jungk, the visioning workshop is a tool that has been used in various settings for the past seventy years. Jungk, a Holocaust survivor, developed the workshop as a tool that would help individuals and organizations become aware of their own agency in the creation of their personal and communal futures, thus offering them a way to become aware of the way their actions in the present affect their futures. These workshops, Jungk hoped, would allow more people to become mindful of their abilities in the creation of desirable futures. The workshops were further popularized in the United States by Elise Boulding and Warren Ziegler, who created the 'Imaging a World Without Weapons Project' and focused their workshops on helping "communities envision futures in which their most pressing problems were solved, to envisioning a world without weapons". ${ }^{7}$

The visioning workshops are generally made up of four steps:

\footnotetext{
${ }^{6}$ For a more thorough explanation of the visioning workshops, please see: Jelena Bodinet's "Futures of Hope" (2016) [15].

${ }^{7}$ Elise Boulding, quoted in [16].
}

1. "Preparation phase": organization and goals of the workshop are explained to the participants.

2. "Critique phase": the participants are asked to identify and investigate the main problem that they wish to focus on, seeking to analyze it thoroughly and understand various aspects of it.

3. "Fantasy phase": during this phase the very crucial work of creating preferred futures images occurs.

4. "Implementation phase": participants are asked to write up a detailed plan for action in the immediate and distant future that will assist them to achieve their preferred imagined futures.

While Jungk utilized several days to complete his visioning workshops and could use more time for the preparation phase, many professors are unable to use as much time for this kind of workshop. In my case, I am only able to set aside two, ninety-minute sessions for this workshop near the end of the semester. In an effort to prepare the students for the workshop using minimal class time, I have developed a set of questions that are used as a reflection paper prompt for the students to complete prior to the start of the workshop. This reflection paper allows students to prepare for the visioning workshop on their own time so that class time could be maximized to focus on other important aspects of the visioning work. The following set of questions are used as the reflection prompt and are based on various works and interviews with the brilliant futurist Sohail Inayatullah:

- What are the things you say to yourself over and over about the state of war and peace in the world?

- Where do these ideas come from? Reflect deeply on your thoughts above.

- Are the ideas you hold about the state of war and peace in the world useful to you?

- Can you create a new story of how you want the world to be/look? What is your vision of a peaceful world? Please be as detailed as possible and try to write from the envisioned future $[15]^{8}$

San Diego City College students seem to be extremely interested in the visioning workshop, but especially so after they have completed the reflection paper and have taken the time to truly think about their futures in a more structured way, the origins of their futures images, and the influences that these images have on their lives. As many futures writers have argued $[17,18]$, our society suffers from a lack of positive futures images; that is, it has become increasingly difficult for most of us to construct clear, positive and constructive images of

\footnotetext{
${ }^{8}$ The questions above focus on the creation of a peaceful world, as that is a large part of the Peace Studies and Futures Studies courses I teach, but they could easily be changed to fit a different paradigm or course requirement.
} 
our personal and communal futures. We are bombarded with other people's visions of the futures; from books, movies, sitcoms, video games, commercials, etc. and, unfortunately, these are often very much dystopian futures - one needs just to peruse the most popular Hollywood movies to come to this realization. Many people, especially those who are younger and impressionable, tend to subconsciously adopt these futures images as their own. San Diego City College students have expressed such 'adopted' futures images numerous times in their personal and communal futures essays, where they are asked to describe their visions of futures thirty years hence. Overwhelmingly, the futures are tech-heavy and at times refer back to a specific source, such as 'The Jetsons' or 'Terminator'. Once immersed in the visioning workshop, the students begin to wake up to the influence that these 'borrowed' futures have had on their own ideas about the futures. This recognition is tied to their abilities to engage in the creation of more original and innovative preferred futures images. In "Futures of Hope" I write:

"Building on the work of Fred Polak, who argued that a lack of positive guiding futures images can lead to a loss of direction and purpose in a society [18], and that of Boulding, who asserted that we cannot create a future we cannot imagine [17], I further propose that the responsibility of the field of futures studies is to create a space in which students can readily engage in the exercise of creating new, creative and preferred images of our global futures... These safe spaces, in which the exploration of positive futures images can take place, can be used as a tool to help empower participants to believe in their agency in the creation of positive changes in their personal and communal futures." [15]

Undoubtedly, the visioning workshop is a tool that can be used to help individuals further understand their role in the creation of their futures. Once individuals become conscious of their agency in the creation of our personal and common futures, they become more aware of how their decisions in the present may effect the outcomes of their short term and long term futures.

\section{Discussion}

"I cannot teach anybody anything, I can only make them think."

- Socrates

Discussions have been used as a teaching tool for centuries, with the Socratic Method, arguably, as one of the most prominent and well known in the Western world. There are various ways that discussions can be utilized in a classroom environment and assist students in acquiring knowledge, while also allowing them to learn to think critically and engage with others in a positive and constructive manner. Discussions are an important part of the classroom environment as they offer a space for the group to come together to share and create knowledge and to ask questions, with no one person having all of the answers. It is also during discussion where the group is able to get to know each other and to learn about each other's personalities, ideas, and thoughts. Over time, the discussions become deeper and more meaningful as they are layered with previous knowledge.

Furthermore, as bell hooks [sic], a prominent educator, feminist and social critic, notes in one of her books: "To engage in dialogue is one of the simplest ways we can begin as teachers, scholars, and critical thinkers to cross boundaries" [19: 130]. hooks is very right in this analysis as the time spent in discussion can assist the professor in the acquisition of new knowledge so as to gain further understanding of the world through the students' experience and analysis. This is the magic of education; if one is able to create a space in which all participants are learning, including the professor, then the space for transformation has been created. Indisputably, letting go of the structure of lecture, and the feeling of power it holds, can be intimidating and daunting for some educators. For most of our lives we have been exposed to the, aforementioned, 'banking' model of education where the educator is in possession of knowledge that is bestowed upon the students through the very organized structure of lecture. In many classrooms, this is still the only structure of learning and, while useful some of the time, lecture can be beautifully interchanged with various structured discussions. Keeping in mind the various contemporary research studies that support the idea that collaborative learning is in fact far more beneficial than the lecture-based model [4] should encourage more educators to adopt such practices in their classrooms and workshops. It is fitting to here enumerate examples of a few discussion formats which have yielded the most favorable results thus far in my courses, including: concentric circles, Socratic inquiry, world cafe, small group discussions, and large circle discussion.

\section{Concentric circles}

Towards the beginning of each semester, I invite colleagues from the local chapter of the 'Alternatives to Violence Project', 9 a volunteer-run conflict transformation program, to visit my class for a ninety-minute workshop. This experiential, community-building workshop allows students to practice both listening and speaking as integral to dialogue, become

\footnotetext{
${ }^{9}$ For more information about AVP, see: http://www.avpcalifornia. org/whatisavp/index.php and http://avpusa.org/.
} 
exposed to non-violent communication tactics, ${ }^{10}$ and learn about alternative conflict transformation strategies. ${ }^{11}$

An integral part of this workshop is concentric circles. First, the class is divided into two groups; one facing in, the other facing out, with each student finding a partner. After the students have had a chance to introduce themselves, the session begins. A facilitator explains the rules and is present to time the session and lead the group through the exercise. The facilitator asks a question that students in either the inner or outer circle are requested to answer, while students in the opposite circle are expected to only listen for a certain amount of time (generally, two to five minutes). Once the facilitator gives a signal, the student roles switch, with the listener becoming the speaker and vice versa. Students in the role of the listener are asked to take the time to listen deeply to their partners, without any kind of verbal response. In the beginning of the exercise, many students have a difficult time with being quiet and just listening without any verbal responses and may need to be reminded of this rule.

After both partners have answered the question, the inner or outer circle is asked to stand up and move one chair to the left or right, until each participant has a new partner. Depending on the goal of the concentric circle, the questions can be chosen by the facilitator to suit the topic at hand. Generally, the exercise starts with more casual questions to allow students time to become comfortable with the process, but with each rotation, deeper questions are asked. In my courses, this exercise is often used as a group-building exercise. Here are some prompts that are given:

- "A movie or book that I love and why."

- "A person I truly admire and why."

- "Something I've learned in my life that has been important to me."

- "A way I have of expressing anger without hurting myself or others."

- "A time I felt most hurt by someone I trusted."

- "One thing I have done I am most proud of."

\section{Socratic inquiry}

While there are various ways that Socratic inquiry can be used and adopted in a classroom setting, ${ }^{12}$ the main point of using this tool is to help students learn to think critically. In my classroom, I utilize the Socratic inquiry method in the form

\footnotetext{
${ }^{10}$ For more information, see Marshall Rosenberg's "Nonviolent Communication" (2015) [20].

${ }^{11}$ For more information, see John Lederach's "The Little Book of Conflict Transformation"(2003) [21].

${ }^{12}$ For a thorough discussion of the Socratic method and its possible uses, see Matt Copeland's Socratic Circles (2005) [22].
}

of circles. Students are given a set of readings to be completed prior to class, along with one or more open-ended, critical thinking questions or prompts. At times, students are also asked to complete a reflection paper, based on the questions/ prompt assigned by the professor, prior to the Socratic circle. The students are briefed on the fact that the professor will not actively participate in the discussion, but will offer minimal assistance, if required. Thus, students are put in a situation where they are obliged to talk among themselves, without the 'towering' figure of the professor.

In preparation for the discussion, chairs are arranged into an inner circle and an outer circle, both facing inward. During the discussion, only students in the inner circle are allowed to speak and participate, while the students in the outer circle only observe and take notes. After some time, their roles switch and the students in the inner circle move to the outer circle and vice versa. At this time, the professor may give the second circle a slightly different prompt or allow them to build off of the conversation of the first group. ${ }^{13}$

\section{Small group work}

In a class of several dozens of students, it can be difficult to engage everyone in the conversation. Small group work can be used as a way to ensure that even the shyest students are able to participate actively and have their voice heard. Here are a few ideas on incorporating small group work in the class:

- Small groups can be utilized as a warm up at the beginning of class. For instance, students can be asked to briefly go over the readings for that day or share insights from their homework.

- Think-Pair-Share: Students are asked to think about a question posed by the instructor and then discuss it with one or two partners. Students could also be asked to write down their thoughts prior to conversing with a partner. After some time (five or so minutes), students are encouraged to share their thoughts with the rest of the class. This activity may also be helpful during lectures; the lecturer may ask questions and put students in pairs to become more actively involved in the material.

- Expert groups: Students are put in small groups of no more than four students and given twenty to thirty minutes to become "experts" on a certain topic or part of the

\footnotetext{
${ }^{13}$ The Socratic circle approach as described here was introduced to me by another Peace Studies professor and colleague, Katie Zanoni. In addition to showing me the process she used in her class, Katie also shared with me an evaluation handout which the students in the outer circle would be asked to fill out while observing the discussion taking place in the inner circle. Each student in the outer circle is put in charge of carefully observing one student in the inner circle, filling out the evaluation handout, and giving their partner feedback and tips for further development.
} 
reading assigned for that day. These experts are then expected to share their expertise with the rest of the class.

- Long-term small group work: students find partners and choose a relevant topic as the focus of a common research question over several weeks. Every student is responsible for one aspect of the research, and is expected to turn in their own research paper independently. The students give a group presentation to share their newfound knowledge.

- "Gallery Walk: Stations or posters are set up around the classroom, on the walls or on tables. Small groups of students travel from station to station together, performing some kind of task or responding to a prompt, either of which will result in a conversation" [23].

\section{The world cafe method}

The World Cafe is yet another method that allows for a structured conversation to take place among students, with minimal input from the instructor. The process is briefly outlined on The World Cafe website:

1) Setting: Create a "special" environment, most often modeled after a café, i.e. small round tables covered with a checkered or white linen tablecloth, butcher block paper, colored pens, a vase of flowers, and optional "talking stick" item. There should be four chairs at each table (optimally) _ and no more than five.

2) Welcome and Introduction: The host begins with a warm welcome and an introduction to the World Café process, setting the context, sharing the Cafe Etiquette, and putting participants at ease.

3) Small Group Rounds: The process begins with the first of three or more twenty minute rounds of conversation for the small group seated around a table. At the end of the twenty minutes, each member of the group moves to a different new table. They may or may not choose to leave one person as the "table host" for the next round, who welcomes the next group and briefly fills them in on what happened in the previous round.

4) Questions: each round is prefaced with a question specially crafted for the specific context and desired purpose of the World Café. The same questions can be used for more than one round, or they can be built upon each other to focus the conversation or guide its direction.

5) Harvest: After the small groups (and/or in between rounds, as needed), individuals are invited to share insights or other results from their conversations with the rest of the large group. These results are reflected visually in a variety of ways, most often using graphic recording in the front of the room. ${ }^{14}$

This kind of a discussion may be used at any point during the semester for various purposes. At times, it may be used as a way to harvest information (i.e. what the students want to focus on and learn further about) or a way to deeply explore an issue (i.e. how can California address the current drought?).

\section{Large circle discussions}

While much of the work occurs in various workshops and small groups, large group discussions serve a very important purpose in the classroom. It is during this time that the whole group comes together and may share their thoughts, experiences and questions. As the discussion facilitator, the professor is responsible for the creation of an atmosphere in which most students will feel comfortable enough to participate in the discussion and share various perspectives.

When properly structured and well organized, large circle discussions become some of the most fruitful processes in my classroom, as they assist the group to accomplish several goals: the group can become well acquainted, thus creating a strong learning community; students become active learners and contribute to the creation of knowledge in the classroom; critical and creative thinking takes place; students take on more power in their own learning and may gear the discussion in the direction that is most useful to them and more. Additionally, time spent in discussion offers a different kind of classroom experience for the educator as well. The educator has to give up some of the power that traditionally comes with the structure of lecture, however, the educator assists in the creation of a space in which she becomes a student and can allow herself to learn, grow and understand the experience of the "other" - the student. This kind of teaching, then, also does something profound for the educator; it frees her to learn from the process and, thus, it contributes to her growth as a person and educator.

\section{Teacher and guest lectures}

"Oh, that Einstein, always cutting lectures... I really would not believe him capable of it." -Hermann Minkowski

\footnotetext{
$\overline{{ }^{14}}$ The World Cafe Method, see http://www.theworldcafe.com/key-conceptsresources/world-cafe-method/.
} 
Lecturing may be one of the oldest teaching methods and is, as previously mentioned, the method mostly utilized in contemporary higher education. Having originated during a time when printed material was not readily available and only a select few had the ability to read and write, lectures were a very useful, if not the only, way to share information with large groups of people. Prior to the invention of the printing press in the mid 1400s, written material was prized highly due to the human-labor-costs associated with each copy, making it a luxury only available to the higher socio-economic groups. During this time, lectures were utilized as a way to transfer knowledge found in written material. The lecturer would often read the printed text to a room full of students copying down as much as they could for their own purposes. The noun "lecture" itself stems from the Latin word lectus, pp. of legere meaning "to read". 15

Over time, lectures have evolved to accommodate everchanging societies and norms. Today, most lecturers utilize audio-visual aids and deliver lectures that are animated and engaging, rather than dully read from pre-written notes. Contemporary research shows that most people learn better by being actively involved in the process, consequently many educators are seeking to utilize more active lecturing styles [4]. Mini lectures, of about fifteen to twenty minutes, may be a great tool to introduce a new topic and cover the most important part of the learning material. At times, several mini lectures can be incorporated into a full class meeting, but attention should be given to ensure that time for active learning is also included. Once the nuts and bolts have been covered through lectures, the class should shift to a different format in an effort to engage even the sleepiest individuals in the back row and allow students to question, probe and reexamine the newly presented information.

As was previously mentioned, there are several ways educators may make their lectures more active. Here are a few specific examples:

- Build in various points in the lecture where students are given the option to ask questions, go back to a specific point and re-examine it, review their notes, compare notes with another student, and/or identify the key points made.

- Pause for short group work at different points in the lecture, asking students to answer a critical thinking question based upon the lecture material (see 'think-pair-share' above).

- One-minute paper: Give students one (or a few) minute(s) to respond to a writing prompt such as: What was the most important concept in the lecture today? What was the most confusing part of the material? The lecturer may collect these papers to gain clarification on the effectiveness of the lecture.

$\overline{{ }^{15} \text { The Latin Dictionary, see http://latindictionary.wikidot.com/verb:legere. }}$
In addition to creating lectures that are more active and participatory, another interesting way to engage and inform students is through guests in the classroom. Guests can fill various roles, in addition to getting students excited about the discipline. Over the years, I have had various guests in my classes, ranging from academic experts in the field, experts in the workplace or individuals who have strong personal stories to share - for example: a sustainability professor to cover the environmental issues we are faced with today and may expect in the future, representatives from such organizations/companies as Institute for the Future (IFTF) to discuss skills necessary to become a professional futurist, and a Holocaust survivor to emphasize some important historical contexts (a very popular visitor in my peace studies classes). At times, it may be difficult for the guest speaker to visit in person, consequently, they may be invited to participate via audio-visual means.

Guest speakers have allowed my students to experience aspects of a field or discipline that I was unable to show or communicate to them personally. This not only has made students more excited about learning, but it has also allowed them to visualize ways that they may be able to move forward with their chosen career. It may be especially difficult for first year undergraduate students to visualize a true professional path in an interdisciplinary subject such as futures studies, but guest speakers can act as real-life examples of existing possibilities.

\section{The pedagogical path to 2030 and beyond}

"No one is born fully-formed: it is through selfexperience in the world that we become what we are." - Paulo Freire

The various pedagogical approaches outlined above are ways in which our traditional, lecture-based classrooms can be transformed into spaces that allow students to attain more than intellectual growth; such should be the classrooms of 2030 and beyond. "Real-world challenges are highly complex, often ill-defined and interdisciplinary in nature, spanning multiple domains (social, economic, political, environmental, legal and ethical). Learners must have opportunities to reflect on their ideas, hone their analytical skills, strengthen their critical and creative thinking capacities, and demonstrate initiative. In particular, the ability to evaluate new inputs and perspectives, build new capacities and strengthen autonomy will be crucial" [4: 15].

It is such student-centered, engaging and cooperative classrooms where students can learn to interact with their peers on a more profound level and consequently gain a new 
understanding of the world, which they share with others. Each of our experiences in the present differs profoundly from others' experience and it is through the sharing of these experiences that we give each other a chance to understand the various presents happening at this time. As we become aware of and begin to understand the various presents that are taking place simultaneously, we may become more conscious of the many futures that are ours to create. The classrooms of the future must allow for such a deep understanding of the 'other' as well as each person's agency in the creation of our futures, as it is only through understanding that we can enact true, meaningful and lasting change. As mentioned above, the challenges that the next generations face, are paramount; and thus the changes in our attitudes, cultures and societies must be sweeping. Educational overhaul can and should play a crucial role in such a transformation.

Open Access This article is distributed under the terms of the Creative Commons Attribution 4.0 International License (http:// creativecommons.org/licenses/by/4.0/), which permits unrestricted use, distribution, and reproduction in any medium, provided you give appropriate credit to the original author(s) and the source, provide a link to the Creative Commons license, and indicate if changes were made.

\section{References}

1. Robinson K (2009) The element: how finding your passion changes everything. Penguin, New York

2. Kerchner C (2011) Learning 2.0: time to move education politics from regulation to capacity building. http://charlestkerchner. com/wp-content/uploads/2011/03/L2First.pdf. Accessed 28 Sept 2016

3. Freire P (1970) Pedagogy of the oppressed. Continuum, New York

4. Scott CL (2015) The futures of learning 3: what kind of pedagogies for the 21st century? UNESCO education research and foresight, Paris. [ERF Working Papers Series, No. 15]. http://unesdoc.unesco. org/images/0024/002431/243126e.pdf. Accessed 28 Sept 2016

5. Nicolescu B (2016) The transdisciplinary evolution of learning. http://www.learndev.org/d1/nicolescu f.pdf. Accessed 1 Aug 2016

6. Kincehloe JL (2008) Critical pedagogy primer. Peter Lang Publishing, New York

7. Dator J (1993) Society as a social invention and you as a social inventor. University of Hawaii, Hawaii Research Center for Futures
Studies. http://www.futures.hawaii.edu/publications/futurestheories-methods/SocialInventor1993.pdf. Accessed 12 Oct 2016

8. Foucault M (1972) The archaeology of knowledge and the discourse on language (trans: Smith AMS). Pantheon

9. McKinley J (2015) Critical argument and writer identity: social constructivism as a theoretical framework for EFL academic writing. http://www.englishappliedlinguistics.com/uploads/2/4/1 19/2419477/social constructivism mckinley 2015.pdf. Accessed on 26 Sept 2016

10. Ertmer PA, Newby TJ (2013) Behaviorism, cognitivism, constructivism: comparing critical features from an instructional design perspective. http://northweststate.edu/wp content/uploads/files/21143_ftp.pdf. Accessed 1 Oct 2016

11. Dvorsky G (2013) The Science behind meditation, and why it makes you feel better. i09 Gizmodo. http://io9.gizmodo.com/howmeditation-changes-your-brain-and-makes-you-feel-b-470030863. Accessed 3 July 2016

12. Meiklejohn J et al. (2010) Integrating mindfulness training into K12 education: fostering the resilience of teachers and students, Springer. http://www.mindfuleducation.org/wpcontent/uploads/2015/01/IMEK-12-ARTICLE-IN-JOURNALMINDFULNESS-ONLINE-VERSION-1.pdf. Accessed 5 July 2016

13. Schonert-Reichl KA, Lawlor MS (2010) The effects of a mindfulness-based education program on pre- and early adolescents' well-being and social and emotional competence. Mindfulness 1:137. doi:10.1007/s12671-010-0011-8

14. Barnes VA, Bauza LB, Treiber FA (2003) Impact of stress reduction on negative school behavior in adolescents. Health Qual Life Outcomes 1:10. doi:10.1186/1477-7525-1-10

15. Bodinet J (2016) Futures of hope: the importance of positive futures images at the community college level. World Future Rev 8(4): 172-179. doi:10.1177/1946756716654693

16. Hurley K et al (2008) Futures studies and feminism. Futures 40: 388-407

17. Boulding E (1992) Can peace be imagined? In: Fahey JJ, Armstrong R (eds) A Peace Reader. Paulist Press, New York

18. Polak F (1973) The image of the future (trans: Boulding E). Elsevier Scientific Pub. Co, Amsterdam

19. hooks b (1994) Teaching to transgress. Routledge, New York

20. Rosenberg M (2015) Nonviolent communication. Puddledancer Press, Encinitas

21. Lederach J (2003) The little book of conflict transformation. Good Books, Intercourse

22. Copeland M (2005) Socratic circles: fostering critical and creative thinking in middle and high school. Stenhouse Publishers, Portland

23. Gonzalez J (2015) The big list of class discussion strategies. Cult of Pedagogy. http://www.cultofpedagogy.com/speaking-listeningtechniques/. Accessed 21 March 2016 